\title{
How Bad is Bad News? Assessing the Effects of Environmental Incidents on Firm Value*
}

\author{
Tommy Lundgren ${ }^{1,2}$ and Rickard Olsson ${ }^{1}$ \\ ${ }^{1}$ Umeå School of Business \\ Umeå University \\ 90183 Umeå, Sweden \\ ${ }^{2}$ Department of Forest Economics \\ Swedish Unversity of Agricultural Sciences \\ 90187 Umeå, Sweden
}

March 31, 2008

\begin{abstract}
Based on a formal model of how investments in corporate social responsibility act upon firm value through goodwill, we derive the hypothesis that under uncertainty bad news are detrimental to goodwill, and subsequently have a negative impact on value. We examine by event study methodology whether bad news in the form of environmental $(\mathrm{EV})$ incidents affect firm value negatively as measured by abnormal returns using a global data set. An EV incident is a company incident allegedly in violation of international norms on environmental issues. We analyze $142 \mathrm{EV}$ incidents 2003-2006. The EV incidents are generally associated with loss of value, but which are not statistically significant, except for incidents for firms in Europe. Furthermore, results indicate that firms with low goodwill capital (high EV risk rating) are associated with relatively larger negative abnormal returns in case of an EV incident.
\end{abstract}

*Financial support was generously provided by the MISTRA research program "Sustainable investments". Rickard Olsson gratefully acknowledges the financial support of Jan Wallanders och Tom Hedelius stiftelse. Dr Lammertjan Dam and Cristiana Manescu provided useful comments. The usual disclaimer applies. 


\section{Introduction}

In this study we assess the effects on firm value of environmental (EV) incidents among firms in a global sample during the years 2003-2006. To accomplish this we make use of daily stock market return data from a panel of the largest firms in the world together with data on EV incidents supplied by GES Investment Services (GES). ${ }^{1}$ The main purpose is to shed light on whether the revelation of $\mathrm{EV}$ incidents has any effect upon firm value. In addition, we also investigate the relationship between incident induced effects and EV risk rating (from GES).

Persuant to conventional economic theory, firms maximize profits subject to technological and other constraints. Without economic incentives like taxes or quantitative regulations, the firm might, for example, "pollute too much", or behave in some other environmentally or socially detrimental manner. A cursory look around business environments today suggests that this point of view might be a trifle old-fashioned. Indeed, some firms appear to spend resources to convince potential consumers and other stakeholders that they are more socially and/or environmentally responsible than what the authorities or society demand. If stakeholders care about the social performance of firms, then incidents such as EV disasters should have a significant impact on the valuation of the firm. In this paper we sketch a model of a socially responsible firm that face uncertianty about future EV incidents. Using the concept of goodwill and assuming that "bad" incidents are detrimental to goodwill capital, we are able to form relevant and testable hypotheses.

The empirical framework in this paper is built on the notion that efficient capital markets ensure that stock prices on any day fully reflect all available information about the present value of the cash flows that a firm is expected to earn in the future (Fama, 1991). Revelation of new information may cause abnormal changes in stock price if it diverge from expectations. If it can be expected that if a firm is prone to incidents the stock price will change less in case of an incident. To assess the effect on firm value of incidents we utilize event study methodology (see e.g. MacKinlay, 1997). An attractive feature of event studies is that the direction of causation is quite clear. The release of information or an incident cause stock value to change, and obviously not the other way around. That is; bad/good EV performance potentially

\footnotetext{
${ }^{1}$ www.ges-invest.com.
} 
induce bad/good financial performance. This may seem trivial at first, but assumes significance given the fact that other type of studies find link between EV performance and financial performance, but the direction of causation is unclear (see e.g. Hay et al, 2005). However, as pointed out by McWilliams et al. (1999), there are several problems with the event study methodology, especially when applied to corporate social responsibility (CSR) data. They claim that event studies only provide estimates of the shortrun impact on shareholders only. Furthermore, event study findings are sensitive to even small changes in research design. In this paper we aim to address the latter by varying the empirical testing methodology.

What can we learn from other event studies on EV performance and firm value? In a review by Margolis and Walsh (2001) it was found that in a total of 13 event studies related to EV events, 6 showed a positive relationship, 3 a negative relationship, 1 both a positve and a negative relationship, and 3 with no effect at all. Positive relationship means that if the event is good news, then firm value also change positively. Hamilton (1995) and Khanna et al $(1998,1999)$ apply event study methodology to the release of information on emissions for the years 1989 - 1994 from the Toxic Release Inventory scheme administered by the US Environmental protection agency (EPA). These studies find statistically significant abnormal returns around the release date of information on emission levels. P. Portney in Hay et al (2005) concludes that empirical evidence concerning the relationship between $\mathrm{EV}$ and financial performance is at best ambiguous. In conclusion; from earlier studies we can not have a clear-cut expectation about what this study may reveal. What result to expect, however, should be proceeded by some theoretical argumentation, which is lacking in most empirical applications up to date. ${ }^{2}$

The present paper augment to some degree the current literature in three different aspects: $(i)$ Adequate and empirically testable hypotheses are derived from a formal micro-economic model of the firm. (ii) The empirical analysis utilize a unique and never used global data-set on EV incidents which enables us to compare between different regions of the world. The use of a relatively large number of EV incidents spread out over many firms and regions is also a novel feature of this study. ( $i i i$ ) As mentioned above, McWilliams et

\footnotetext{
${ }^{2}$ There are, however, a few studies concerned with CSR and economic performance which are more rigorous when it comes to theoretical underpinnings. See e.g. theme issues in Structural Change and Economic Dynamics, Paton and Siegel (2005), and Journal of Productivity, Paul and Siegel (2006).
} 
al (1999) claim that event studie results are sensitive to variation in methodology, particularly the abnormal return test metric. In response we use several different test metrics which can be found in the literature (see Patell, 1976, and Boehmer et al, 1991 for discussion about test metrics and their pros and cons). We also attempt to bring order among the different measures and their inter-relations.

The remainder of this paper is organized as follows. Next we present some theoretical underpinnings which help clarify the economic mechnisms behind CSR and why bad news potentially lowers firm value. The paper proceeds to describe the data used in the empirical analysis. Subsequent sections describe empirical framework and results. Finally, we offer a summary and concluding remarks.

\section{Theory}

Why would firm value be affected by environmentally related incidents? How can we model this mechanism at firm level, and can we draw any useful information from such a model to help us to state relevant hypotheses in the empirical investigation below? This section briefly sketch a model that links CSR and bad news to a firm's profits and hence the value of the firm. The theory builds on the green firm model developed by Kriström and Lundgren (2003) and Lundgren (2003). The model framework outlined here builds on specifically on Lundgren (2007), which generalize the green firm model to many types of CSR and introduces explicitly potential costs and benefits of CSR. Basically, we augument this model by adding an uncertainty component to account for the arrival of bad news.

Firms balance the costs and benefits of CSR on the margin. Costs could be associatied with actual investments, promotion, and crowding out effects, while benefits could be a price premium, and possibly lower cost of capital (risk reduction) and/or labor (wage differentials). For a more detailed discussion about how benefits and costs are incorporated into the functions of revenues and costs of the firm, see Lundgren (2007). In the sequel, we simply assume that pressures and motivations from different stakeholders will create incentives to engage in projects related to CSR. These efforts are summarized in a stock of goodwill capital.

The firm's management problem is to invest in CSR projects to augment goodwill in an optimal way. Goodwill can also decrease by either deliberate 
disinvestment in goodwill or by bad publicity, which occur with some degree of randomness. This is introduced formally later. That is, the firm can opt to augment or reduce a stock of goodwill by investing or disinvesting in CSR. The stock of goodwill acts on profits through both revenues and costs, and therefore, as we shall see, changes in goodwill has direct impact on firm value.

Let us formally define firm profits, $\pi$, at time $t$ as

$$
\pi(t)=\pi(g(t), G(t), H(t))
$$

denoting investment in CSR $g(t),{ }^{3}$ and the stock of goodwill $G(t) . H(t)$ is a measure of "financial health" determined by variables that are not related to CSR, e.g., conventional inputs such as labor and capital, and financial variables such as debt to equity ratio. This profit function is assumed to be decreasing at an increasing rate in $g(t)$, and increasing at a decreasing rate in $G(t)$. Given the above functional form, the objective or value function for the management problem is (supressing time sub-index hereafter)

$$
V=\max _{g} \int_{t=0}^{\infty} e^{-r t} \pi\left(g, G, H^{*}\right) d t
$$

where $V$ is the value of the firm at time $t$, and $e^{-r t}$ is a discount factor where $r$ is the discount rate. $H^{*}$ is given at this stage to simplify and focus on the CSR-investment problem. Think of it as a two-stage decision problem; the manager(s) first maximize profits with respect to conventional inputs and other variables, then profits are maximized with respect to CSR investments and goodwill capital.

Assume that goodwill capital develop over time as follows,

$$
\begin{aligned}
\dot{G} & =\frac{d G}{d t}=g-\delta G, \\
G_{t=0} & \geq G_{0},
\end{aligned}
$$

where $\delta$ is the decay rate of goodwill, and $G_{0}$ is a given starting value for goodwill at time $t=0$. The management problem is thus to chose $g$ as to maximize the future stream of discounted profits given the equation of motion for goodwill capital.

\footnotetext{
${ }^{3}$ This control variable can be considered multi-dimensional as CSR can take many forms. However, for simplicity, we treat CSR investment as a one-dimensional control variable. This does not change the basic idea we want to convey here.
} 
From the optimality conditions postulated by control theory, we can derive the following relations that must hold (sub-index denotes partial derivatives hereafter):

$$
\begin{aligned}
\lambda & =-\pi_{g}, \\
\dot{\lambda} & =(r+\delta) \lambda-\pi_{G},
\end{aligned}
$$

which simply states that the shadow price of goodwill ${ }^{4}$, denoted $\lambda$, is equal to the marginal cost of investing in CSR, and that the differential equation for the shadow price of goodwill is governed both by the marginal cost of CSR-investment, $\pi_{g}=\lambda$, and marginal benefits of the goodwill stock, $\pi_{G}$.

The system is in steady state when $\dot{\lambda}=0$ and $\dot{G}=0$, which, from 4 , implies that

$$
-\pi_{g}=\frac{\pi_{G}}{(r+\delta)}
$$

That is, in steady state, the marginal cost of investing in one extra unit of CSR is equal to the benefits of goodwill it creates discounted by the rate of return plus the rate of depreciation of goodwill.

A useful result, especially for the empirical application in this paper, is that the change in the value of the firm is directly related to the change in goodwill stock. This insight stems from a general result, see e.g. Brock (1998), which says that the time derivative of the value function in an optimal control problem of such type that we skecth here, is directly related to the net changes in all stocks in the model. That is, $\dot{V}=\sum_{i} \lambda_{i} \dot{S}_{i}$, where $\lambda_{i}$ is the shadow price of stock $i$, and $S_{i}$ is the $i^{\text {th }}$ stock. Since we only have one stock, goodwill, we can state the following;

$$
\dot{V}=\lambda \dot{G}
$$

This result suggest that changes in goodwill, positive or negative, as a result of investing or disinvesting in CSR, will have direct effect on the value of the firm.

How can we introduce a model feature that mimic bad news arriving over time? It is assumed that bad news harm goodwill, and thus potentially lowers firm value (depending on market sensitivity to such issues, etc). Here we model this mechanism so that it enters the management problem explicitly

\footnotetext{
${ }^{4}$ The theoretically "correct" price.
} 
via the equation of motion for goodwill, 3. Assume that bad news arrive according to a stochastic process (e.g. Brownian motion or Poisson jump), then we can write the equation of motion for goodwill, 3, as

$$
d G=(g-\delta G) d t+\theta(G) d P
$$

or equivalently,

$$
\dot{G}=g-\delta G+\theta(G) \frac{d P}{d t}
$$

where $\theta(G) d P$ is the random component of goodwill evolution, and the magnitude of the "impact" parameter $\theta$ depend on level of goodwill capital. For example, assume that in each point in time there is a probability of bad news arriving so that the time path of goodwill takes a "dive" according to some pre-specified stochastic process. To solve this stochastic optimal control problem is cumbersome, to say the least. However, we can make a humble conjecture without resorting to stochastic calculus. ${ }^{5}$ Given that $\dot{V}=\lambda \dot{G}$ and 7 we can write

$$
\dot{V}=\lambda\left(g-\delta G+\theta(G) \frac{d P}{d t}\right) .
$$

From the relationship depicted above we can see that, all else constant, should the evolution of goodwill take a "dive" because of bad news, $d P<0$, promted by e.g. reports of EV disaster, then the value of the firm also change in the same direction. Now we are equipped to test this theoretical proposition using empirical data on firm stock returns and reported incidents related to the environment. The relevant hypothesis to test would be if incidents have any effect on goodwill, and as a consequence also on firm value. Given that bad news or EV incidents are defined as $d P<0$, and if the shadow price of goodwill, $\lambda$, and the "impact parameter", $\theta(G)$, are both positive, then the value of the firm should be negatively affected by EV incidents. Note also that the impact parameter potentially depend on $G$, but whether this effect is increasing, decreasing, or non-existing (with respect to $G$ ), is ultimately an empirical question.

\footnotetext{
${ }^{5}$ For technical expositions of stochastic models similar to the one sketched here, see Gould (1970), or Tapiero $(1975,1978)$.
} 


\section{Data}

In this section we present the data used in the empirical application. The empirical analysis make use of EV incident data, EV risk ratings, and stock and market index returns. We begin by describing the incident data, then proceed to the financial data, and finally a brief description of risk ratings.

\subsection{Incidents}

The incident data were supplied by GES, who describes the data as follows:

"Since 2003, GES Alert Service provides clients with weekly news briefings on recently reported company incidents allegedly in violation of international norms on Environmental ... issues. The news are forwarded to the client within a week after obtained through GES' screening. By this systemized process, GES Alert Service singles out news of special investor concern which often take long before being highlighted in mainstream media or disappear in the torrent of news. [...] The GES Alert Service covers major world indexes." 6

The data we used contain firm identification codes and incident reporting dates (to GES clients). The incidents we analyze emanate from 2003-2006. The actual incident date may differ from reporting date. This means that for a given reporting date, there is some uncertainty about when the incident actually occured. We deal with this by using different length of the period investigated around the event. More details on window length below.

\footnotetext{
${ }^{6}$ www.ges-invest.com, Oct. 3, 2007.
} 
Table 1. Distribution of incidents and firms across sectors

\begin{tabular}{lccc}
\hline \hline Sector & Incidents & Firms & Frequency \\
Oil \& Gas & 21 & 7 & 3.0 \\
Basic Materials & 64 & 28 & 2.3 \\
Industrials & 22 & 11 & 2.0 \\
Consumer Goods & 17 & 12 & 1.4 \\
Healthcare & 3 & 3 & 1 \\
Consumer Services & 5 & 4 & 1.2 \\
Telecommunications & 1 & 1 & 1 \\
Utilities & 5 & 4 & 1.2 \\
Financials & 2 & 2 & 1 \\
Technology & 2 & 2 & 1 \\
\hline Totals & 142 & 74 &
\end{tabular}

Table 1 shows that the frequency of EV incidents per firm is highest for sectors Oil \& Gas, Basic Materials, and Industrials, known to be environmentally challenging.

Table 2. Distribution of incidents across firms

\begin{tabular}{ccc}
\hline \hline Incident/firm & Firms & Incidents \\
1 & 42 & 42 \\
2 & 15 & 30 \\
3 & 10 & 30 \\
4 & 4 & 16 \\
5 & 0 & 0 \\
6 & 1 & 6 \\
7 & 1 & 7 \\
8 & 0 & 0 \\
9 & 0 & 0 \\
10 & 0 & 0 \\
11 & 1 & 11 \\
\hline Totals & 74 & 142
\end{tabular}

Table 2 show that one firm has 11 incidents, but most firms have only 1 incident during the period studied. 


\begin{tabular}{cc} 
Table 3. Distribution of incidents across years \\
\hline \hline Year & Incidents \\
2003 & 17 \\
2004 & 18 \\
2005 & 39 \\
2006 & 68 \\
\hline Total & 142
\end{tabular}

Table 3 suggest that more incidents occur in recent years; 2006 has four times as many incidents as 2003. One probable reason is that GES has increased the number of firms monitored in the most recent years.

\begin{tabular}{lccc}
\multicolumn{4}{c}{ Table 4. Distribution of incidents across countries } \\
\hline \hline Country & Incidents & Firms & Frequency \\
Australia & 5 & 3 & 1.7 \\
Germany & 7 & 5 & 1.4 \\
Canada & 12 & 7 & 1.7 \\
Danmark & 2 & 2 & 1.0 \\
Finland & 4 & 2 & 2.0 \\
Japan & 2 & 2 & 1.0 \\
Holland & 1 & 1 & 1.0 \\
Switzerland & 6 & 5 & 1.2 \\
UK & 16 & 5 & 3.2 \\
US & 87 & 42 & 2.1 \\
\hline Totals & 142 & 74 &
\end{tabular}

According to table 4, the great majority of incidents in our sample happens to US firms, but according to relative frequency, the UK has most incidents per firm.

\subsection{Financial data}

Data for calculating daily stock and MSCI World Index and Country US dollar returns, adjusted for dividends net of tax and corporate actions, were retrieved from Thomson Datastream (www.datastream.com), as were sector classifications according to Industry Classification Benchmark (ICB) and country classification according to Thomson Datastream. 


\subsection{Risk ratings}

GES assigns stocks a specific and a general EV risk rating. A firm's general EV risk rating ( $\mathrm{A}, \mathrm{A}-, \mathrm{B}+, \mathrm{B}, \mathrm{B}-, \mathrm{C}+, \mathrm{C})$ is intended to reflect the $\mathrm{EV}$ risk of the firm's industry. The specific EV risk rating (a, a-, b+, b, b-, c+, c) indicates the particular EV risk of a given firm. The ratings are converted from letters to numbers in the subsequent empirical analysis. The specific EV risk rating is derived through analysis of the company along more than 60 dimensions based on international standards for EV management and industry-specific key indicators for EV performance, among other things. Information sources used in the analysis process include official company documents, dialogue with companies, non-governmental organizations, the media and GES partners in the Sustainable Investment Research International Group (www.ges-invest.com and private communication with GES representatives).

\section{Empirical framework}

The effects of the incidents on firm value are analyzed as follows. ${ }^{7}(i)$ During an estimation period prior to an incident, we estimate normal return with the market model. (ii) In an event window, separated from and subsequent to the estimation period, we estimate abnormal returns surrounding an incident. (iii) The abnormal returns are calculated for each period in the event window, i.e., the actual return minus normal return. (iv) Cumulative abnormal returns for each event and event window are calculated, and these are then averaged across events. ( $v$ ) Test if cumulative abnormal returns are significantly different from zero.

Let us formalize this procedure. The market model (see e.g. Sharpe, 1964) is used to estimate normal returns in the estimation period prior to

\footnotetext{
${ }^{7}$ See any standard finance econometrics textbook, e.g. the event study chapter in Campbell et al. (1997).
} 
each incident ${ }^{8}$

$$
\begin{aligned}
r_{i \tau} & =\alpha_{i}+\beta_{i} r_{m \tau}+\epsilon_{i \tau} \\
i & =1 \ldots N, \text { incidents, } \\
\tau & =1 \ldots T, \text { days in estimation period, }
\end{aligned}
$$

where in this case $N=142$, and $T=88$ (about four months). OLS regressions are performed using realizations of $r_{i \tau}$ and $r_{m \tau}$ to obtain estimates of $\alpha_{i}$ and $\beta_{i}$ (the residual is assumed to have white noise properties). The estimate of the variance of the observed residuals is given by,

$$
\sigma_{i}^{2}=\frac{1}{T} \sum_{\tau=1}^{T} \epsilon_{i \tau}^{2}
$$

The estimated market model is used to predict returns in the event window. The prediction errors are abnormal returns. Abnormal returns are defined as,

$$
\begin{aligned}
a r_{i t} & =r_{i t}-\left(\alpha_{i}+\beta_{i} r_{m t}\right) \\
t & =-t_{b} \ldots t_{0} \ldots+t_{e} \\
L & =t_{b}+t_{0}+t_{e}
\end{aligned}
$$

where $t_{0}$ is the event day, and $t_{b}$ (begin day) and $t_{e}$ (end day) defines the event window lenght, $L$. If OLS assumptions hold also in the event window, then the expected abnormal return is zero, and there is no serial correlation or covariance with market returns. That is,

$$
\begin{aligned}
E\left[a r_{i t}\right] & =0 \\
\operatorname{cov}\left[a r_{i t}, a r_{i s}\right] & =\left\{\begin{array}{c}
0 \text { for } t \neq s \\
C_{i t} \sigma_{i}^{2} \text { for } t=s
\end{array}\right\}, \\
\operatorname{cov}\left[a r_{i t}, r_{m t}\right] & =0 \\
t & =t_{b} \ldots t_{0} \ldots t_{e}, \text { and } \\
i & =1 \ldots N .
\end{aligned}
$$

\footnotetext{
${ }^{8}$ We could use more elaborate models to estimate normal return, e.g. the Fama-French four factor model. However, as pointed out by MacKinlay (1997), adding risk factors to the simple market model does not improve the predictive power very much.
} 
Further, we also make the following assumption,

$$
\operatorname{cov}\left[a r_{i t}, a r_{j t}\right]=\left\{\begin{array}{c}
0 \text { for } i \neq j \\
C_{i t} \sigma_{i}^{2} \text { for } i=j
\end{array}\right\}
$$

This means no cross-sectional dependence of abnormal returns in event window. ${ }^{9}$ The function $C_{i t}$ (see Patell, 1976) corrects event window variance to account for possible increase in variation outside the estimation period,

$$
\begin{aligned}
C_{i t} & =1+\frac{1}{T}+\frac{\left(r_{m t}-E\left[r_{m \tau}\right]\right)^{2}}{\sum_{\tau=1}^{T}\left(r_{m \tau}-E\left[r_{m \tau}\right]\right)^{2}}, \\
E\left[r_{m \tau}\right] & =\frac{1}{T} \sum_{\tau=1}^{T} r_{m \tau} .
\end{aligned}
$$

Using 10, 11, and 14 we can define the standardized abnormal return as,

$$
\operatorname{sar}_{i t}=\frac{a r_{i t}}{\sqrt{C_{i t} \sigma_{i}^{2}}}
$$

which is approximately unit normal. Define the normalized sum (over $L$ ) of cumulative standardized abnormal returns of event $i$ as,

$$
\operatorname{scar}_{i L}=\sum_{t=1}^{L} \frac{a r_{i t}}{\sqrt{L C_{i t} \sigma_{i}^{2}}}=\frac{1}{\sqrt{L}} \sum_{t=1}^{L} s a r_{i t} .
$$

The main reason for using standardized abnormal returns is that it prevents securities with large variances from dominating the test. ${ }^{10}$ The multiplication of the denominator by $\sqrt{L}$ scales the daily standard deviation to a $L$-day standard deviation corresponding to the event window length. Finally, form the normalized sum (over $N$ ) to obtain the following test statistic,

$$
T_{1}=\operatorname{scar}_{N L}=\frac{\sum_{i=1}^{N} \operatorname{scar}_{i L}}{\sqrt{N}} .
$$

\footnotetext{
${ }^{9}$ This assumption may seem superfluous since the market model implicitly assumes that all cross-sectional dependence is captured by the market. We include this assumption explicitly only because we relax it later.

${ }^{10}$ Standardizing means each observation is weighted in inverse proportion to the standard deviation (here corrected by $C_{i t}$ ). Brown and Warner $(1980,1985)$ conclude that in principle standardized abnormal returns is superior to unstandardized, but in very short-horizon event studies, it makes little difference what measure is used.
} 
$T_{1}$ is a $t$-statistic, used in e.g. Patell (1976), which can be used to test whether incidents have any significant effect on returns during the specified event window.

A risk when forming $\sum_{i=1}^{N} s_{c a r}$ is that possible event induced variance is ignored. Boehmer et al (1991) suggests an augmented test statistic which they call the standardized cross-sectional method. ${ }^{11}$ This test statistic is found by dividing the $T_{1}$-test statistic by a cross-sectional standard error,

$$
\Omega_{N}=\sqrt{\frac{1}{N-1} \sum_{i=1}^{N}\left(\operatorname{scar}_{i L}-\sum_{i=1}^{N} \frac{\operatorname{scar}_{i L}}{N}\right)^{2}} .
$$

The appropriate $t$-distributed test statistic is then,

$$
T_{2}=\frac{T_{1}}{\Omega_{N}}
$$

That is, if $\Omega_{N}=1$ then $T_{1}$ and $T_{2}$ are equal.

A third, more simple, test statistic can be derived from unstandarized abnormal returns. Cumulative abnormal returns in an event window is,

$$
\operatorname{car}_{i L}=\sum_{t=1}^{L} a r_{i t},
$$

so that average cumulative abnormal returns over all events can be written,

$$
\operatorname{acar}_{N L}=\frac{\sum_{i=1}^{N} \operatorname{car}_{i}}{N}
$$

A (simple) $t$-distributed test statistic of abnormal returns is then specified as,

$$
T_{0}=\frac{\operatorname{acar}_{N L}}{\sqrt{\frac{1}{N^{2}} \sum_{i=1}^{N} L \sigma_{i}^{2}}}=\frac{\operatorname{acar}_{N L}}{\frac{\sqrt{L}}{N} \sqrt{\sigma_{i}^{2}}}=\frac{\operatorname{acar}_{N L}}{\sqrt{L} \bar{\sigma}_{i}},
$$

where the denominator is the square root of the variance of $a c a r_{N L}$. Note that this test will not be sensitive to changes in variance due to out-of-estimationperiod forecasting or event induced variance.

\footnotetext{
${ }^{11}$ In an extensive review of the event study literature, Khotari and Warner (2006) concludes that specification bias arising due to cross-correlation in returns can be a serious problem, especially for long-horizon tests of price performance.
} 
The tests $T_{0}, T_{1}$, and $T_{2}$ are performed on abnormal returns to investigate the following hypotheses,

$$
\begin{aligned}
& H_{0}: \text { abnormal returns }=0, \\
& H_{A}: \text { abnormal returns }<0 .
\end{aligned}
$$

Connecting to the theory section, recall equation 8 , this means we want to test whether the shadow price of goodwill, $\lambda$, and the impact parameter, $\theta(G)$, are jointly positive. The tests are performed for three different windows: $+/-20,+/-7$, and $+/-3$ days surrounding the event day. The motivation for this is to account for uncertainty about the actual incident date.

In addition, we investigate the relation between abnormal returns and firm characteristics by fitting a linear cross-sectional regression model. Specifically, variations of the following equation is estimated,

$$
s c a r_{i}=\mathbf{x}_{i} \mathbf{a}^{\prime}+\mathbf{E V R R}_{i} \boldsymbol{\gamma}^{\prime}+v_{i},
$$

where $\mathbf{x}_{i}$ and $\mathbf{E V R R} \mathbf{R}_{i}$ are vectors of firm characteristics and EV risk ratings respectively, and a and $\gamma$ are the associated parameter vectors. Environmental risk ranking has two dimensions, firm specific and industry specific. As firm characteristics we use sector dummys. The purpose of this excercise is to test whether a proxy for goodwill capital (the EV risk ratings) have any effect - positive, negative or non at all - on the magnitude of abnormal returns; i.e., in equation 8, we want to test if $\partial \theta(G) / \partial G \lesseqgtr 0$.

Next we proceed to present results from the event study and cross-sectional regressions.

\section{Results}

There are 74 firms with incidents in the sample and all of them have at least one incident. Prior to the start of each incident window, 88 days, market model estimates are generated for the firms having incidents as well as for all other firms in the data universe (see table 5 below). 


\begin{tabular}{|c|c|c|c|}
\hline & $\alpha$ & $\overline{\bar{\beta}}$ & $\bar{R}^{2}$ \\
\hline Incident firms $\left(139^{*}\right)$ & 0.000 & 1.025 & 0.372 \\
\hline Other firms $\left(49224^{*}\right)$ & 0.000 & 0.989 & 0.355 \\
\hline
\end{tabular}

According to table 5 there are no significant differences between incident firms and other firms in the estimation periods ( 88 days prior to incidents). Furthermore, the alpha and beta values are - in both cases - not out of expectation (around zero and unity, respectively).

In table 6-9 below we present results for the tests $T_{0}, T_{1}$ and $T_{2}$, for three different event windows sizes. Abnormal returns and the impact of EV incidents are tested for four different geographical areas; global, US, non-US, and Europe (Europenan countries with EV incidents are found within the EURO zone, Denmark, UK, and Switzerland).

\begin{tabular}{lccc}
\multicolumn{2}{c}{ Table 6. Test results for whole sample (Global) } \\
\hline \hline \multirow{3}{*}{ Event window } & \multicolumn{3}{c}{ Global } \\
\cline { 2 - 4 } Nobs & $+/-20$ days & $+/-7$ days & $+/-3$ days \\
acar & 137 & 140 & 140 \\
$T_{0}$ & -0.013 & -0.003 & -0.002 \\
$T_{1}$ & -1.650 & -0.695 & -0.557 \\
$T_{2}$ & -1.053 & -0.648 & -0.576 \\
\hline
\end{tabular}

Table 6 shows that when using all the data we have, abnormal returns are negative in all three windows, but only near statistical significance (a $t$-score of -1.650 is just inside the $10 \%$ level) when applying the simplest test, $T_{0}$, on the $+/-20$ day window. 
Table 7. Test results for US only

\begin{tabular}{lccc}
\hline \hline & \multicolumn{3}{c}{ US } \\
\cline { 2 - 4 } Event window & $+/-20$ days & $+/-7$ days & $+/-3$ days \\
Nobs & 84 & 86 & 86 \\
acar & -0.008 & -0.001 & 0.002 \\
$T_{0}$ & -0.785 & -0.168 & 0.587 \\
$T_{1}$ & 0.056 & -0.106 & 0.333 \\
$T_{2}$ & 0.048 & -0.117 & 0.393 \\
\hline
\end{tabular}

Table 7 presents test results for the US only. Abnormal returns are negative in the two larger window, but positive in the $+/-3$ day window. Non of test statistics are anywhere close to being statistically significant.

Table 8. Test results excluding US

\begin{tabular}{lccc}
\hline \hline & \multicolumn{3}{c}{ non-US } \\
\cline { 2 - 4 } Event window & $+/-20$ days & $+/-7$ days & $+/-3$ days \\
Nobs & 53 & 54 & 54 \\
acar & -0.021 & -0.007 & -0.008 \\
$T_{0}$ & -1.661 & -0.907 & -1.614 \\
$T_{1}$ & -1.730 & -0.912 & -1.348 \\
$T_{2}$ & -1.520 & -1.105 & -1.334 \\
\hline
\end{tabular}

In table 8 results for all geographical areas except US are entered. Abnormal returns are negative in all three event windows. For the $+/-20$ window, $T_{0}$ and $T_{1}$ are statistically significant on the $10 \%$ level. However, the more sophisticated test, $T_{2}$, is not significant at any defendable significance level.

Tables 6, 7 and 8 suggests that US firm returns are not sensitive to EV incidents. Outside US there seems to be some degree of sensitivity of returns with respect to incidents according to test statistics $T_{0}$ and $T_{1}$ in the $+/-20$ window. 
Table 9. Test results for Europe*

\begin{tabular}{lccc}
\hline \hline & \multicolumn{3}{c}{ Europe } \\
\cline { 2 - 4 } Event window & $+/-20$ days & $+/-7$ days & $+/-3$ days \\
Nobs & 35 & 36 & 36 \\
acar & -0.036 & -0.012 & -0.006 \\
$T_{0}$ & -3.104 & -1.738 & -1.315 \\
$T_{1}$ & -2.490 & -1.220 & -0.749 \\
$T_{2}$ & -2.448 & -1.505 & -0.669 \\
\hline
\end{tabular}

*Europe in this case is EURO zone countries, together with

Denmark, UK, and Switzerland.

Test statistics for Europe are found in table 9. Abnormal returns are negative and notably higher in magnitude compared to abnormal returns in other geographical areas (tables 6-8). Furthermore, in Europe we see that all three tests are statistically significant at $5 \%$ level for the largest event window. Shrinking the window down to $+/-7$ days shows that the significance of the tests also shrink, with only the simple $T_{0}$-test being significant on the $10 \%$ level. The European area results supports our theoretical model's prediction of a positive price for goodwill and a positive impact parameter; i.e., incidents cause goodwill to decrease and, as a consequence, firm value also decrease.

Finally, we use the regression model specified in equation 21 to analyze if the magnitude of abnormal returns are correlated to a proxy for goodwill capital, the EV risk ratings, for companies in Europe (where the abnormal returns were found statistically significant). Several variants of the regression model were estimated; with and without sector dummys, and also elaborating with different combinations of firm specific and sector specific EV risk. There were problems, however, with multicollinearity when including both sector dummys and industry or sector specific EV risk, and therefore we do not present results from those regressions. Table 10 summarize the results from running two regressions: Model 1) a constant and firm specific and sector specific EV risk as separate independent variables; Model 2) a constant and an aggregate measure of sector and firm specific risk. 
Table 10. Cross-sectional regression results and diagnostics.

\begin{tabular}{lcc}
\hline \hline Independent variables & Model 1 & Model 2 \\
Constant & $1.805(2.101)$ & $1.472(1.928)$ \\
Sector EV risk & $-0.559(-2.438)$ & \\
Firm EV risk & $-0.866(-1.868)$ & \\
Sector + firm EV risk & & $-0.674(-2.497)$ \\
Adjusted $R^{2}$ & 0.147 & 0.158 \\
$F$-test $(p$-value $)$ & 0.048 & 0.019 \\
Nobs & 29 & 29 \\
\hline Note: $t$ - & &
\end{tabular}

Note: $t$-values within parenthesis. Dep. var. $=s c a r_{i}$

The results in table 10 show that the model using the aggregate measure (model 2) has slightly superior explanatory power. From model 1 we see that firm specific risk is statistically significant on $10 \%$ level in model 1, while sector specific risk is significant on $5 \%$ level. The negative slope parameter estimates in both models imply larger abnormal losses for relatively risky firms in risky sectors.

\section{Summary and concluding remarks}

In this paper we examine by event study methodology if environmental (EV) incidents affect firm value negatively as measured by abnormal returns. The analysis use a global database on incidents not used in research before from GES Investment Services, which monitors some thousand stocks in the major world indexes for incidents. We analyze all (142) EV incidents in the database which covers the years 2003-2006. The main findings are that the incidents are generally associated with negative returns, but which are not statistically significant, except for for firms in Europe. There is also evidence pointing to US firm values being unsensitive to EV incidents, implying that firm stakeholders have different views on EV incidents in Europe and the US. The results are robust with respect to a number of variations in test methodology. Furthermore, we find evidence that EV risk (our goodwill proxy) have a negative and significant statistical effect upon the magnitude of abnormal returns in Europe, implying that higher EV risk (low goodwill) is associated with a more extensive loss of firm value compared to firms with low EV risk (high goodwill). A reasonable explanation for this is that firms with high 
risk are also subjected to more severe EV incidents, causing more economic and reputational damage.

The findings in this paper suggests that a firm's voluntary effort to avoid EV incidents may be more pronounced in Europe than in the US, since "punishment" from stakeholders is more likely (here in the form of loss in firm value). This means that policy directed towards designing public disclosure programs of $\mathrm{EV}$ performance ${ }^{12}$, which increase transparency with respect to $\mathrm{EV}$ issues, have the potential to be successful when it comes to motivating firms to voluntary internalize externalities from production. ${ }^{13}$ Furthermore, Rauscher (2006), in a study of voluntary emisson reductions, suggest that if there exist social reward (punishment) for corporate social responsibiliy (CSR) (irresponsibility), then traditional EV policy, e.g. taxes, may hamper the private provision of CSR. That is, social rewards may be crowded out by EV regulation in the shape of a tax or regulation.

Without doubt there are numerous problems with the event study methodology and the incident data at hand. The actual date of the incident is not known and we have not controlled for other events in the event window that might affect returns. The analytical framework also lack mechanisms accounting for expectations. Future studies could explore the possibilies of applying alternative methods to analyze the effects of EV incidents. This would complement the present event study and potentially shed some additional light on the issue of $\mathrm{EV}$ incidents and impact on firm valuation.

\section{$7 \quad$ References}

Boehmer, E., J. Musumeci, A. B. Poulsen (1991), Event-study methodology under conditions of event-induced variance, Journal of Financial Economics 30, 253-72.

Brock, W. (1998), Optimal control and economic dynamics, in The New Palgrave Dictionary of Economics (eds) J. Eatwell, M. Milgate adn P. Newman, Palgrave Publishers, Houndmills, 721-26.

\footnotetext{
${ }^{12}$ E.g., like the Toxic Release Inventory published by the US Environmental Protection Agency.

${ }^{13}$ Note that If effects of bad and good news are symmetrical, then social rewards should increase firm value in case of good news according to the findings in the present paper. If such symmetry exists has to be further analyzed.
} 
Brown, S. J. Warner (1980), Measuring security price performance, Journal of Financial Economics 8, 205-58.

Brown, S. J. Warner (1985), Using daily stock returns: the case of event studies, Journal of Financial Economics 14, 3-32.

Fama, E. (1991), Efficient capital markets: II, Journal of Finance 46, 1575-1617.

Gould, J.P. (1970), Diffusion processes and optimal advertising policy, Microeconomic foundations of Employment and Inlflation Theory, Phelps E.S. et al eds., W. W. Norton, 338-68.

Hamilton, J.T. (1995), Pollution as News: Media and Stock Market Reactions to the Toxics Release Inventory Data, Journal of Environmental Economics and Management 28, 98-113.

Hay, B.L., R.N Stavins, R.H.K. Vietor (eds) (2005), Environmental protection and the social responsibilities of firms - perspectives from law, economics, and business, Resources for the Future, Washington, DC, USA.

Khanna, M., W.R.H. Quimio, D. Bojilova (1998), Toxics Release Information: A Policy Tool for Environmental Protection, Journal of Environmental Economics and Management 36, 243-266.

Khanna, M. and L.A. Damon (1999), EPA's Voluntary 33/50 Program: Impact on Toxic Releases and Economic Performance of Firms. Journal of Environmental Economics and Management 37, 1-25.

Khotari, S. P., J. B. Warner (2006), "Econometrics of Event Studies", Handbook of Corporate Finance: Empirical Corporate Finance, Volume A (Handbooks in Finance Series), Elsevier/North-Holland, Ch. 1.

Kriström, B., T. Lundgren (2003), Abatement investment and green goodwill, Applied Economics 35(18), 1915-21.

Lundgren, T. (2003), A real options approach to abatement investment and green goodwill, Environmental and Resource Economics 25, 17-31.

Lundgren, T. (2007), On the economics of corporate social responsibility, SIRP Working Paper Series, www.sirp.se, Sweden.

MacKinlay, A. C. (1997), "Event Studies in Economics and Finance," Journal of Economic Literature Vol. XXXV, (1997).

Margolis, J., J. Walsh (2001), People and profits? Mahwah, NJ: Lawrence Erlbaum associates.

McWilliams, A., D. Siegel, S. H. Teoh (1999), Issues in the Use of the Event Study Methodology: A Critical Analysis of Corporate Social Responsibility Studies, Organizational Research Methods 2(4), 340-65. 
Patell, J. (1976), Corporate forecasts of earnings per share and stock price behavior: Empirical tests, Journal of Accounting Research, 246-76.

Paton, D., D. Siegel, eds, (2005), The economics of corporate social responsibility, Structural Change and Economic Dynamics 16, 309-431.

Paul, C. M., D. Siegel, eds, (2006), Special issue on corporate social responsibility (CSR) and economic performance, Journal of Productivity Analysis 26(3), 207-87.

Rauscher, M. (2006), Voluntary emission reductions, social rewards, and environmental policy, CESifo Working Paper No. 1838.

Sharpe, W. F. (1964), Captial asset prices: A theory of market equilibrium under conditions of risk, Journal of Finance 19(3).

Tapiero, C.S. (1975), On-line and adaptive optimum advertising control by a diffusion approximation, Operations Research 23(5), 890-907.

Tapiero, C.S. (1978), Optimum advertising and goodwill under uncertainty, Operations Research 26(3), 450-63. 